\title{
Optimal mitigation strategies with negative emission technologies and carbon sinks under uncertainty
}

\author{
Sabine Fuss • Wolf Heinrich Reuter • Jana Szolgayová • \\ Michael Obersteiner
}

Received: 29 February 2012 / Accepted: 23 December 2012 / Published online: 25 January 2013

(C) The Author(s) 2013. This article is published with open access at Springerlink.com

\begin{abstract}
In recent years a body of literature has arisen on the topic of how to compose the optimal portfolio of mitigation options. The focus has been mainly on options involving shifts from high- to low- or even negative-carbon technologies. Natural sinks play an important role in any attempt to stabilize atmospheric $\mathrm{CO}_{2}$ and usually enter as a constant term in the overall carbon budget. In this paper, we introduce natural sinks to the carbon management problem and analyze the implications for negative emission technology deployment and the overall mitigation strategy. Amongst other sensitivity analyses, we also investigate the impact of uncertainty in the carbon sink, which we find to raise the importance of negative emissions in the mitigation portfolio significantly lowering the cost of the policy mix.
\end{abstract}

\section{Introduction}

One important ingredient for achieving stabilization targets of $450 \mathrm{ppm}$ or lower, which has moved to the centre of the debate over the past decade, is the option of deploying Negative Emission Technologies (NETs) also known as Carbon Dioxide Removal (CDR) options (Obersteiner et al. 2001). Azar et al. (2010), for example, test three different large-scale energy models and find a significant proportion of biomass-based energy with carbon capture and storage (BECCS) as part of an energy mix optimized to stabilize at $350 \mathrm{ppm}$. While this is a promising avenue for future mitigation strategy, the question arises what the interaction between NETs and other elements of the mitigation portfolio is.

This article is part of a Special Issue on "Carbon Dioxide Removal from the Atmosphere: Complementary Insights from Science and Modeling” edited by Massimo Tavoni, Robert Socolow, and Carlo Carraro.

S. Fuss $(\bowtie) \cdot$ W. H. Reuter · J. Szolgayová $\cdot$ M. Obersteiner

International Institute for Applied Systems Analysis, Schlossplatz 1, 2361 Laxenburg, Austria e-mail: fuss@iiasa.ac.at

\section{W. H. Reuter}

Department of Economics, Vienna University of Economics and Business, Althanstrasse 39-45, 1090 Vienna, Austria

\section{J. Szolgayová}

Department of Applied Mathematics and Statistics, Comenius University, 84248 Bratislava, Slovakia 
The importance of accounting for natural sinks when determining the optimal policy mix to avoid temperature increases beyond $2^{\circ} \mathrm{C}$ has been widely discussed, e.g. in the context of Reduced Emissions from Deforestation and Degradation (REDD). However, different models project rather different trajectories for global sinks, as can be observed through the discrepancies between estimates in the IPCC's Third and Fourth Assessment Reports for terrestrial carbon sinks (Fischlin et al. 2007).

While a number of existing studies look at the opportunities of REDD and the implications of its implementation in much detail (e.g. Bosetti and Lubowski 2010), none of them really considers its risk profile to determine the optimal composition of a mitigation portfolio given the uncertainty surrounding these sinks (Fuss 2010). In this paper, we therefore model the natural sink stochastically and as a function of atmospheric Greenhouse Gas (GHG) concentration accounting for possible climate feedbacks. We analyze different emissions targets and identify the best hedging strategies in the technosphere given the uncertainty in the biosphere with explicit focus on their interrelation and potential climate feedbacks. Finally, we focus the analysis on the potential for BECCS, which is by no means certain, as estimates differ across the supply chain starting with sustainably harvestable biomass for bioenergy and ending with the potential for safe and permanent storage.

\section{Literature discussion}

The relevant literature concerns both methodologies to find optimal mitigation strategies in the face of uncertainty and the different options (e.g. abatement, BECCS) underlying such strategies in the presence of natural (stochastic) sinks. In addition, the literature on the effect of including sinks in mitigation optimization is discussed. Starting with the literature on mitigation portfolios, it is important to note that previous analyses of optimal policy portfolios have typically neglected NETs (e.g. Gerlagh et al. 2009). Evidently, this is in the process of changing, as most global assessments now acknowledge the importance of emissions turning negative in order to achieve the two-degree target. For example, the Global Energy Assessment (GEA 2012) finds that almost zero or negative emissions are needed in the second half of the century for all their scenarios. The new scenarios by the International Energy Agency, ETP2012, (IEA 2012) also show a rapid deployment of BECCS being essential for reaching the two-degree target with large potential in industry. While these assessments are deterministic, the focus of this paper is on the effect of uncertainty on the composition of the optimal mitigation portfolio.

Both the PAGE (Policy Analysis of the Greenhouse Effect) model, which has been used in the Stern Review (Hope 2006), and the Dynamic Integrated model of Climate and the Economy (DICE) (Nordhaus 2008), for example, consider the impacts of climate change and the effects of parametric uncertainty. In a stochastic version of DICE, Nordhaus (2008) includes normal distributions of the growth rate of total factor productivity (TFP), the sensitivity of temperature change to changes in GHG concentrations and the sensitivity of reductions in output to temperature changes. He finds that uncertainty does not play a large role for climate policy decisions, which is in contrast to the findings of PAGE and also our findings. ${ }^{1}$ In addition, our interest is more focused on the availability of NETs, which are neither included in the stochastic DICE version nor in PAGE.

\footnotetext{
${ }^{1}$ Ackerman et al. (2010) amongst others point to possible reasons for this finding, which are related to the use of a quadratic damage function and normally distributed temperature in DICE, which can lead to underestimation of welfare losses from unmitigated climate change.
} 
In a very recent paper by McInerney et al. (2012), the DICE model with parametric uncertainty is further explored for the impact that different decision criteria might have on abatement and the robustness of mitigation strategies. They find that criteria giving more weight to the mitigation strategy's performance under worst-case scenarios lead to more near-term abatement and higher robustness, i.e. strategies trade off a low drop in expected performance against a large increase in the performance in the worst case scenario. The aim of McInerney et al's paper is thus rather on expanding methods for decision-making and does neither explore NETs nor the importance of sinks and their associated uncertainties.

Bosetti et al. (2008) use the stochastic version of the regional hybrid integrated assessment model WITCH to analyze the optimal mitigation portfolio given uncertainty about the future stabilization target. They find a large hedging effect implying that overall mitigation is much higher than in the deterministic case, with public R\&D into energy efficiency and investment into carbon-free technology (nuclear energy) being the main elements of the mitigation portfolio. There are no strategies pertaining to carbon sinks and also no NETs.

Lemoine et al. (2012) have implemented a dynamic portfolio of abatement, R\&D, and NET policies under an exogenous $\mathrm{CO}_{2}$ constraint and with stochastic technological change. Their results show that near-term abatement is not sensitive to the availability of R\&D policies, but if NETs are expected to become available, near-term abatement will be reduced substantially In this paper, we also include NETs, but we are less interested in strategies on R\&D. Instead, we focus on (a) the relatively unexplored effect that the inclusion of natural sinks and the uncertainty that surrounds them has on robust and cost-minimizing mitigation strategies and overall policy costs and (b) the impact of expectations about BECCS potentials.

Further on the different strategies, a considerable body of literature is currently emerging on BECCS individually. BECCS was first put forth as an option by Obersteiner et al. (2001), Kraxner et al. (2003) and later in the 2005 Working Group III Report of the IPCC. Even though generally recognized as an option to potentially reduce emissions by up to $10 \mathrm{Gt}$ of $\mathrm{CO}_{2}$ per year (IEAGHG 2011), certain caveats remain. These include uncertainties surrounding storage potentials, issues of social acceptance and possible problems of leakage (van der Zwaan and Gerlagh 2009). While the latter demonstrates that BECCS has its own risks, which do not apply to NETs not using geological storage (by e.g. applying biochar to soils (Lehmann 2007)), we adopt in this paper a relatively conservative number of $2,100 \mathrm{Gt} \mathrm{CO}_{2}$ for the storage potential, which we find not to be a binding constraint in the analysis, unless we substantially lower the target or significantly lower the BECCS potential. ${ }^{2}$ In addition, any assessment of BECCS relies heavily on the assumption of sustainable forestry and minimization of indirect land use change effects due to increased demand for biomass (see e.g. Kraxner et al. 2012).

Next to BECCS and other carbon dioxide removal (CDR) techniques ${ }^{3}$, the role of accounting for and management of natural sinks have come to the forefront of the public debate about mitigation since Marrakech 2001. Efforts to analyze the implications from land use and management changes for carbon policy started even earlier (e.g. Ahlig et al. 1997) and forest carbon sequestration in particular has been at the centre of continuing research (e.g. Stavins 1999, and Sohngen and Mendelsohn 2003). Marginal costs of carbon sequestration have been found to be competitive and partially much cheaper than those of the options related to energy technologies. Van't Veld and Plantinga (2005) implement a dynamic model of optimizing

\footnotetext{
${ }^{2}$ This number is the sum of the IPCC's (2005) estimates for storage in oil and gas fields, saline formations and coal beds. Note that subsequent estimates have been substantially higher (e.g. Dooley et al. 2005), so this can be considered a conservative constraint.

${ }^{3}$ In particular, we include into our analysis direct air capture, which has been studied more closely recently (see e.g. American Physical et al. 2011).
} 
abatement and mitigation through sequestration under different expectations of carbon price developments. They find that for increasing prices abatement is unchanged and that also the absolute amount of sequestration in the mitigation portfolio might ultimately not be lower. However, the timing of sequestration changes, as rising carbon prices represent an incentive to delay, which is unique for sequestration activities. This is broadly in line with earlier findings by Sohngen and Mendelsohn (2003), but at odds with the general "consensus" that sequestration should happen as early as possible, which is due to that literature's assumption on constant carbon prices according to van't Veld and Plantinga (2005).

Notwithstanding the findings from such deterministic analysis, many uncertainties remain with respect to enhancing sinks, not only pertaining to management, but especially concerning the nature and dynamic behavior of the sinks themselves. Le Quéré et al. (2009) analyze trends and volatility in terrestrial and ocean sinks and find major uncertainties related to the former. Canadell and Raupach (2008) emphasize the risk emanating from disturbances such as fire and insect outbreaks having turned Canadian forests from a sink (before 2000) to a source of $\mathrm{CO}_{2}$. They point to the uncertainty about the future size and stability of the terrestrial carbon sink and stock and also stress the uncertainty related to parameters underlying the analysis such as the magnitude of the fertilization effect. As such properties have implications for the composition of the optimal mitigation portfolio, we account for this by modeling sinks stochastically. Furthermore, feedbacks ${ }^{4}$ of decisions to sinks need to be taken into account: more GHG emissions will lead to a certain degree of fertilization up to a specific point. Such effects on the sink are modeled explicitly in the study at hand, but we also conduct sensitivity analyses to shed more light on the implications that uncertainty around this effect have on the composition of the optimal mitigation portfolio. Finally, geo-engineering has been suggested as a "savior of last resort" in the context of global warming. One suggestion is to inject sulphur into the stratosphere to achieve a temporary cooling effect (Crutzen 2006), which can be categorized as a solar radiation management (SRM) strategy. As this is a very immature field with little data and evidence on side effects such as eventual acidification of oceans due to high $\mathrm{CO}_{2}$ absorption, we have chosen to not consider such an option in our analysis. ${ }^{5}$

\section{Model}

In this paper we use a stylized model to analyze the optimal dynamic mitigation strategy in the presence of NETs, $\mathrm{CO}_{2}$ sinks and uncertainty. A global decision-maker plans abatement and NET deployment bound by a cumulative emission target over the 21 st century. The decision-maker selects the most cost-effective policy plan with two available options: (1) abatement and (2) deployment of NETs/CDR consisting of BECCS and Direct Air Capture (DAC). The technologies differ in their cost structure and mitigation levels. We assume abatement to be viable up to the level of base emissions with its marginal cost depending on the fraction of base emissions abated. For the deployment of NETs, the marginal costs for each technology are constant, BECCS being significantly cheaper, but its potential limited. DAC, on the other hand, is available at any mitigation level. The $\mathrm{CO}_{2}$ sink is modeled similar to Friedlingstein et al. (2006) to account for the feedback between atmospheric $\mathrm{CO}_{2}$ concentration, the change in temperature and the sink, with additional stochastic shocks representing extreme events like forest fires, pests, etc (Moore and Allard 2008). The probability of shock occurrence is modeled as being positively dependent

\footnotetext{
${ }^{4}$ Note that the feedback we are referring to are concentration-carbon feedbacks and not climate-carbon feedbacks. For a thorough literature overview of the latter type, the reader is referred to Lemoine (2010a, b).

${ }^{5}$ See in this context also the recommendations by The Royal Society (2009) to the IPCC.
} 
on the cumulative emissions. The focus of the analysis will be the role of NETs deployment in the optimal policy plan and its interrelation with the stochastic $\mathrm{CO}_{2}$ sink.

We assume a global decision-maker whose objective is to select in each period $t$ a policy portfolio minimizing the cost of ultimately meeting an exogenous constraint $e^{*}$ on the cumulative $\mathrm{CO}_{2}$ emissions of the whole planning horizon. The options available are different levels of abatement $\left\{a_{t}\right\}_{t=1}^{T-1}$ and NET deployment $\left\{n_{t}\right\}_{t=1}^{T-1}{ }^{6}$. The maximum level of abatement in each period is given by the business-as-usual (BAU) emissions $e_{t}$, the marginal abatement and NET cost functions are denoted $\operatorname{MAC}\left(a_{t}, e_{t}, t\right), \operatorname{MNC}\left(n_{t}, e_{t}, t\right)$ respectively. The increase in cumulative $\mathrm{CO}_{2}$ emissions in period $t, \mathrm{ghg}_{\text {incr }}$, is given by

$$
\text { ghg }_{\text {incr }}=e_{t}-a_{t}-n_{t}-s_{t+1}
$$

with $S_{t+1}$ denoting the sink capacity at the beginning of period $t+1$, i.e. the end of period $t$. The sink is modeled following Friedlingstein et al. (2006) with the addition of random shocks $X_{t}$ to account for extreme events (Moore and Allard 2008). The evolution of the cumulative $\mathrm{CO}_{2}$ emissions $g h g_{t}$ and sink $S_{t}$ is modeled by coupled difference equations

$$
\begin{gathered}
g h g_{t+1}=g h g_{t}+e_{t}-a_{t}-n_{t}-s_{t+1} \\
s_{t+1}=s_{t}+\beta g h g_{i n c r_{t}} X_{t}
\end{gathered}
$$

where $\beta$ is the land (ocean) carbon sink sensitivity to atmospheric $\mathrm{CO}_{2}$. We model the probability that the shock $X_{t}$ occurs as being positively dependent on the current cumulative emissions $g h g_{t}$, and the probability distribution of the shock $X_{t}$ is given by

$$
X_{t}=\left\{\begin{array}{c}
1-\delta, \text { with probability } \alpha+(1-\alpha)\left(\sum_{i=1}^{t} e_{i}\right)^{-1} g h g_{t} \\
1, \text { with probability }(1-\alpha)\left(1-\left(\sum_{i=1}^{t} e_{i}\right)^{-1} g h g_{t}\right)
\end{array}\right.
$$

where $\delta$ is the size of the negative shock to the sink and $\alpha$ is a constant increasing the likelihood of a negative shock.

The whole model can be thus formulated as

$$
\min _{a_{t}, n_{t}} \mathbb{E}\left[\sum_{t=1}^{T-1}(1+r)^{-t}\left(\int_{0}^{a_{t}} \operatorname{MAC}\left(x, e_{t}, t\right) d x+\int_{0}^{n_{t}} \operatorname{MNC}\left(y, e_{t}, t\right) d y\right)\right]
$$

subject to ${ }^{7}$

$$
\begin{array}{ll}
s_{t+1}=\frac{1}{1+\beta X_{t}} s_{t}+\left(1-\frac{1}{1+\beta X_{t}}\right)\left(e_{t}-a_{t}-n_{t}\right) & \text { for } t=1,2, \ldots, T-1 \\
g h g_{t+1}=g h g_{t}+e_{t}-a_{t}-n_{t}-s_{t+1} & \text { for } t=1,2, \ldots, T-1 \\
s_{1}=0 & \\
g h g_{1}=0 & \text { for } t=1,2, \ldots, T-1 \\
a_{t} \in\left[0, e_{t}\right] &
\end{array}
$$

\footnotetext{
${ }^{6}$ The controls are discretized down to $10 \mathrm{GtCO}_{2}$, where rounding is always downwards, so as to avoid a situation where the target is reached due to upward rounding.

${ }^{7}$ Note that we abstain from assigning an absolute value to the initial sink, as such estimates are surrounded by large uncertainty, and instead adopt an equilibrium view of the sink, where the initial value is normalized to zero.
} 
As formulated, the model is a stochastic optimal control model and can be solved backwards. Each model run yields the optimal mitigation portfolio in each period conditional on previous sink shocks and abatement and NET policies and also the associated expected cost, which is later on referred to as portfolio cost. This enables us to derive the expected values of respective mitigation options, assuming the decision-maker behaves optimally and the sink capacity follows Eq. (3). At the same time, the different cost structure of BECCS and DAC allows us to identify which technology is deployed and to which extent. For the analysis of the results, we report expected abatement, BECCS and DAC levels in the respective periods, and also the total levels for the whole planning period.

\section{Data}

In the analysis we consider three periods - 2010-2029, 2030-2049 and 2050-2099, chosen so that they approximately correspond to the near-term, intermediate-term and long-term periods for which the $\mathrm{CO}_{2}$ emission goals are discussed. The Business as Usual (BAU)

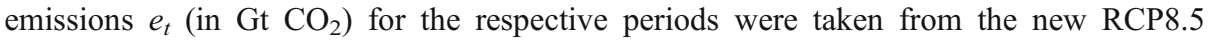
prepared for the Fifth Assessment Report of the IPCC.

$$
e_{1}=820, e_{2}=1171, e_{3}=5721
$$

While the new reference concentration pathway can be considered a revision of the A2 scenario with assumptions derived from the latter, RCP8.5 also takes into account enhancements in land use and land cover change projections (Riahi et al. 2011). The cumulative $\mathrm{CO}_{2}$ emissions of the $21^{\text {st }}$ century have to meet the specified constraint $e^{*}$, cumulative emissions being considered a robust indicator of total temperature change (Allen et al 2009; Matthews et al 2009; National Research Council 2011). We set the exogenous constraint in the baseline to $880 \mathrm{Gt} \mathrm{CO}_{2}$, which corresponds to a year $2100 \mathrm{CO}_{2}$ concentration of $435 \mathrm{ppm}$ (Lemoine et al. (2012), assuming a constant airborne fraction of 0.45 (Denman et al. 2007)), other levels are used for sensitivity analysis and discussed later.

The land (ocean) carbon sink sensitivity $\beta$ representing the feedback between atmospheric $\mathrm{CO}_{2}$ concentration, the temperature and the sink, is from Friedlingstein et al. (2006), who provide numbers for the so-called "gain factor", which estimates the effect of climate-induced changes in the carbon budget on the rate of increase of atmospheric $\mathrm{CO}_{2}$. We use the average of the land and ocean factors reported in the paper as the sensitivity estimate for the feedback between atmospheric $\mathrm{CO}_{2}$ concentration, the temperature and the sink, i.e. $\beta=0.4261$. The levels of the sink shock parameters $(\alpha, \delta)$ are varying between the model runs, as their impact on the robustness of results is tested.

As for the discount rate, we assume a rate of $5 \%$ per year in the base case. However, we acknowledge the huge debate surrounding discounting in climate mitigation analysis and test for a range of $0-10 \%$.

For the functional form of the abatement cost, we assume that its average cost depends on the fraction of BAU emissions abated. For its estimation, marginal abatement cost curves (MAC) have been taken from the literature (van Vuuren et al. 2009), where several bottomup and top-down approaches were compared with the IPCC AR4 results. They show that especially at low costs - there are hardly any differences in MACs and they fit an exponential function, which we use as the MAC function:

$$
\operatorname{MAC}\left(a_{t}, e_{t}, t\right)=0.95 e^{9.35 \frac{a_{t}}{e_{t}}} U S \$
$$


This implies that it is possible to reduce emissions in 2030 by around $50 \%$ at 100 US $\$ / \mathrm{tCO}_{2}$ compared to the baseline.

A second type of cost function applies to the deployment of NETs. We represent NETs as BECCS and DAC. We assume that DAC is available at any level, its marginal cost according to American Physical Society et al. (2011) being estimated to amount to 550 US\$ for a scenario considered to be realistic. The potential of BECCS, on the other hand, is constrained. According to Hoogwijk et al. (2005), the final energy supply based on bioenergy from land-based feedstocks (without biofuels) for the A1 scenario of the IPCC in 2030 is $41 \mathrm{EJ} /$ year, in 2050 it is $132 \mathrm{EJ} /$ year and in 2100 it is $225 \mathrm{EJ} /$ year. For the calculation of BECCS constraints, we assume that no more BECCS can be installed than can be served by fully exploiting these biomass potentials. This gives us (seeing that a power plant produces approximately $7 \mathrm{GJ} / \mathrm{tCO}_{2}$ captured (Rhodes and Keith 2005) ${ }^{8}$ ) the maximum negative emission potential of BECCS for electricity deployment as $5.85 \mathrm{GtCO} 2 /$ year in 2030, $18.8 \mathrm{GtCO}_{2} /$ year in 2050 and $32.1 \mathrm{GtCO}_{2} /$ year in $2100 .^{9}$ For the costs, Gough and Upham (2011) report an upper-limit BECCS cost of $105 \mathrm{US} \$ / \mathrm{tCO}_{2}$. While presenting a review of many expert opinions, they conclude that care needs to be taken not to overestimate the BECCS potential mainly because the cost of connecting bio-processing infrastructure with $\mathrm{CO}_{2}$ storage sites is not well researched and also because scenarios of global bioenergy potential remain contentious. The latter is largely due to the difficulty of fully accounting for competition for land, which again depends on other uncertain parameters, and which could change the cost for BECCS (Rhodes and Keith 2005).

The implications for DAC are that, even if its marginal costs fall significantly, "coherent $\mathrm{CO}_{2}$ mitigation would result in DAC deployment only after nearly all significant point sources of fossil $\mathrm{CO}_{2}$ emissions are eliminated, either by substitution of non-fossil alternatives or by capture of nearly all of their $\mathrm{CO}_{2}$ emissions" (American Physical Society et al. 2011). The marginal NET cost function $\operatorname{MNC}\left(n_{t}, e_{t}, t\right)$ thus becomes:

$$
\operatorname{MNC}\left(n_{t}, e_{t}, t\right)= \begin{cases} & \text { if } \mathrm{n}_{\mathrm{t}}<117, G t C O_{2} \text { and, } t=1 \\ 105 U S \$ & \text { if } \mathrm{n}_{\mathrm{t}}<377 G t C O_{2} \text { and } t=2 \\ & \text { if } \mathrm{n}_{\mathrm{t}}<1605 G t C O_{2} \text { and }, t=3 \\ 550 U S \$ & \text { else }\end{cases}
$$

It should be noted that, as not all parameterizations could benefit from a full calibration to empirical work, the relative effects of the various variables are analysed and extensive sensitivity analyses with respect to the numbers of the key parameters is conducted in order to ensure the robustness of our results. The goal of the analysis, therefore, is not to provide specific levels of the policy variables, but rather to assess the robustness of the optimal portfolios and identify the crucial parameters affecting them.

\footnotetext{
${ }^{8}$ This value follows from three parameters: the net efficiency, which is $28 \%$ (HHV), the carbon intensity per ton of biomass, which is $24 \mathrm{~kg} / \mathrm{C}$ per GJ, and the carbon capture rate-equal to the fraction of fuel carbon captured as $\mathrm{CO}_{2}$ - being $44 \%$ in Rhodes and Keith (2005),

${ }^{9}$ Note that an alternative way of handling maximum BECCS potential would be to consider ecological impacts for different deployment levels. While not practical for the purposes of our modeling. Smith and Torn in this issue provide a good example of such an implementation.
} 


\section{Results}

The base case uses the data introduced in Section 4 and ignores any shock to the sink, i.e. the values for the shock size $(\delta)$ and the probability of a shock $(\alpha)$ are zero. We would expect the NETs deployment to be sensitive to changes in the perception of future costs, i.e. the discount rate the decision-maker employs, as NETs are quite expensive and thus will be shifted into the future the more one discounts future cost. A variable often discussed is the feedback effect of the carbon sink to the $\mathrm{CO}_{2}$ in the atmosphere (Higgins and Harte 2012), i.e. $\beta$. The higher this factor, the less mitigation is needed in total. As NETs are an expensive option to mitigate emissions, we thus expect the NETs deployment to fall with an increase in the feedback effect. Connected to both uncertainty in the climate agreement negotiation process (Bosetti et al. 2008), but also scientific uncertainty with respect to e.g. climate sensitivity (Caldeira et al. 2003), we also do not know the "true" cumulative emission constraint the decision-maker must target. A lower target would increase the deployment of NETs as more mitigation is needed in total. On the other hand, due to the uncertainty in the sink, NETs can act as a reversal option in the last period in case of overshooting the target because of a shock. Finally, the size and probability of occurrences of sink shocks are uncertain in the literature so far. Due to the argument above, we expect NETs deployment to rise in the last period with increases in either the probability or the size of shocks to the sink.

Our baseline results, as summarized in Table 1, without any shock to the sink (i.e. $\delta=0$ and $\alpha=0$ ) show that totally $4,260 \mathrm{GtCO}_{2}$ are mitigated by abatement and $1,605 \mathrm{GtCO}_{2}$ by NETs. All mitigation by NETs occurs in the last period and by deployment of BECCS $\left(1,605 \mathrm{GtCO}_{2}\right.$ is the maximum amount of BECCS in the third period). Abatement on the other hand is split between the three periods (first period: $140 \mathrm{GtCO}_{2}$, second period: $360 \mathrm{GtCO}_{2}$, third period: $3,760 \mathrm{GtCO}_{2}$ ). The corresponding $\mathrm{MACs}$ of the last unit mitigated are increasing from $4.7 \$ \mathrm{US}$ per $\mathrm{tCO}_{2}$ in the first period to $443.4 \$ \mathrm{US}$ per $\mathrm{tCO}_{2}$ in the third period, which is just short of the $\$ 550 / \mathrm{tCO}_{2}$ that would bring forth $\mathrm{DAC}$. In the third period the abatement option is used for the first $2,879 \mathrm{GtCO}_{2}$, afterwards deployment of BECCS is cheaper and employed to the maximum potential $\left(1,605 \mathrm{GtCO}_{2}\right)$. Finally, abatement is used until the MAC rise up to the cost of DAC.

These baseline results are now tested for their sensitivity to changes in key parameters. We begin by assuming different levels of discount factors in Eq. (5). The results using discount rates of $0 \%, 2.5 \%, 5 \%, 7.5 \%$ and $10 \%$ are shown in Fig. 1 . There are two main points of interest at the extreme values of the scale: if the discount rate increases, it is optimal to shift more and more mitigation into the last period, even above the point where the relatively expensive DAC is deployed. For example, at a discount rate of $10 \%$ the optimal portfolio consists of abatement of $60 \mathrm{GtCO}_{2}$ in period 2 and $3,880 \mathrm{GtCO}_{2}$ in period 3, BECCS of $1,605 \mathrm{GtCO}_{2}$ and DAC of

Table 1 Values for baseline scenario

\begin{tabular}{lcccc}
\hline & $2010-2029$ & $2030-2049$ & $2050-2099$ & Total \\
\hline Baseline Emissions [GtCO2] & 820 & 1,171 & 5,721 & 7,712 \\
Abatement [GtCO2] & 140 & 360 & 3,760 & 4,260 \\
NETs [GtCO2] & 0 & 0 & 1,605 & 1,605 \\
Sinks [GtCO2] & 203 & 383 & 381 & 967 \\
Atmospheric GHG [GtCO2] & 477 & 905 & 880 & \\
MAC last abatement unit [\$/t CO2] & 4.70 & 17.00 & 443.40 \\
\hline
\end{tabular}

Prices are $\$$ MACs per $\mathrm{t}$ of $\mathrm{CO}_{2}$, all other values in $\mathrm{GtCO}_{2}$ 

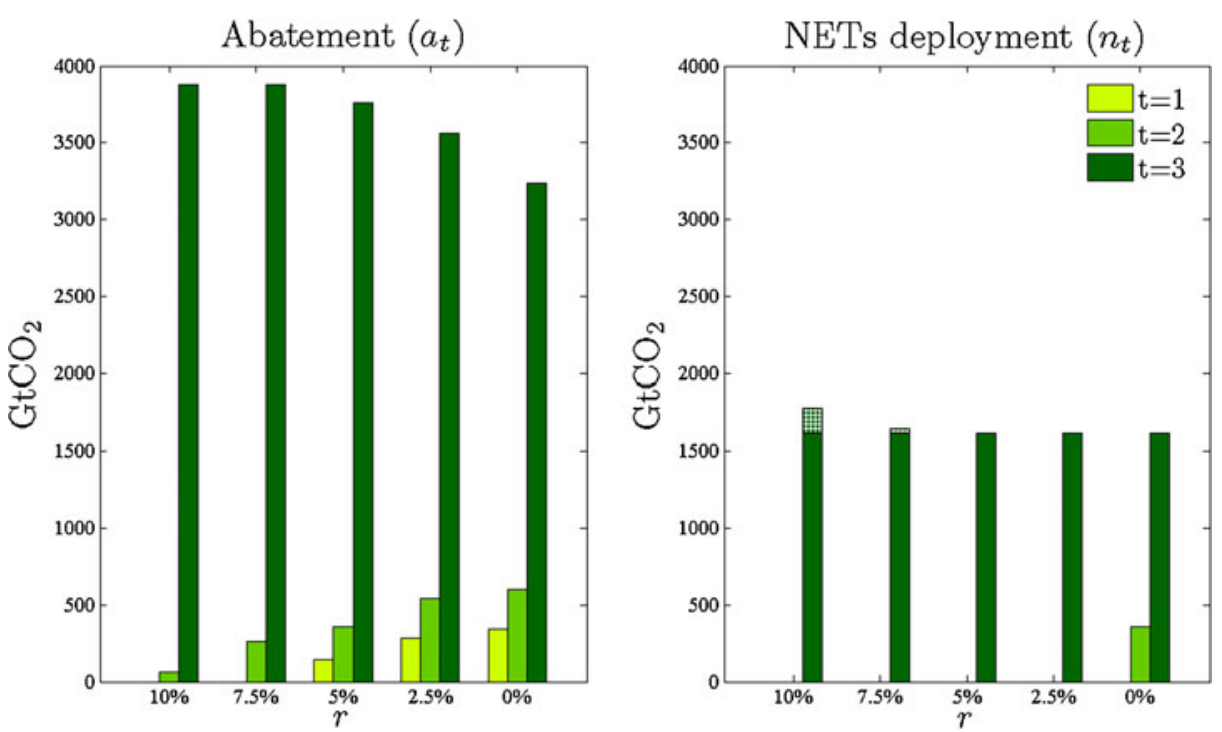

Fig. $1 \mathrm{GtCO}_{2}$ mitigated for different discount rates in time periods 2010-2029, 2030-2049, 2050-2099

$175 \mathrm{GtCO}_{2}$ in period 3. Thus the cost of the last unit mitigated by NETs in Period 3 will be $\$ 550 / \mathrm{t}$, given the assumptions of the model. At the opposite end, without discounting, it becomes optimal to deploy BECCS already in the second period and shift more and more abatement towards the first periods. In our example the abatement quantities in period 1, 2 and 3 are $340 \mathrm{GtCO}_{2}, 600 \mathrm{GtCO}_{2}, 3,240 \mathrm{GtCO}_{2}$ respectively ${ }^{10}$ and the $\mathrm{BECCS}$ deployment in period 2 and 3 is $377 \mathrm{GtCO}_{2}$ and $1,605 \mathrm{GtCO}_{2}$ respectively at a discount rate of $0 \%$. This implies that without discounting about $40 \%$ of the emissions are already mitigated in the first period and even $80 \%$ of the new emissions in the second period.

Furthermore, we investigate the sensitivity of our results to changes in the sink's sensitivity to atmospheric $\mathrm{CO}_{2}, \beta$. While there seems to be a general agreement that $\mathrm{CO}_{2}$ fertilization does have a positive impact on the sink, the exact number for the sink's sensitivity to atmospheric $\mathrm{CO}_{2}$ is uncertain. The results of the sensitivity analysis with respect to $\beta$ displayed in Fig. 2 illustrate that the deployment of BECCS (and DAC) is indeed very much dependent on this sensitivity. For the value taken from Friedlingstein et al. (2006) or higher, NETs occupy a relatively stable share in the mitigation portfolio, which is equal to the maximum BECCS potential. The amount of abatement, on the other hand, decreases as the sink takes up more of the emissions. However, when the feedback effect is smaller, the amount of $\mathrm{CO}_{2}$ abated with NETs increases, i.e. deployment of DAC starts and increases (for a $\beta$ of 0.3 deployment of $\mathrm{DAC}$ is $35 \mathrm{GtCO}_{2}$, for 0.2 it is $215 \mathrm{GtCO} 2$ and for $\beta$ of 0 deployment of $\mathrm{DAC}$ is $695 \mathrm{GtCO}_{2}$ ). The lower the sink's sensitivity $\beta$, the larger these increases are. This result is not surprising, as it implies that the amount of "free" mitigation through uptake by natural sinks decreases and NETs have to make up for the difference.

${ }^{10}$ The MACs of the last unit abated in the respective periods are: $\$ 45.86 / \mathrm{CCO}_{2}, \$ 114.38 / \mathrm{t} \mathrm{CO}_{2}$ and $\$ 189.41 / \mathrm{t}$ $\mathrm{CO}_{2}$. 

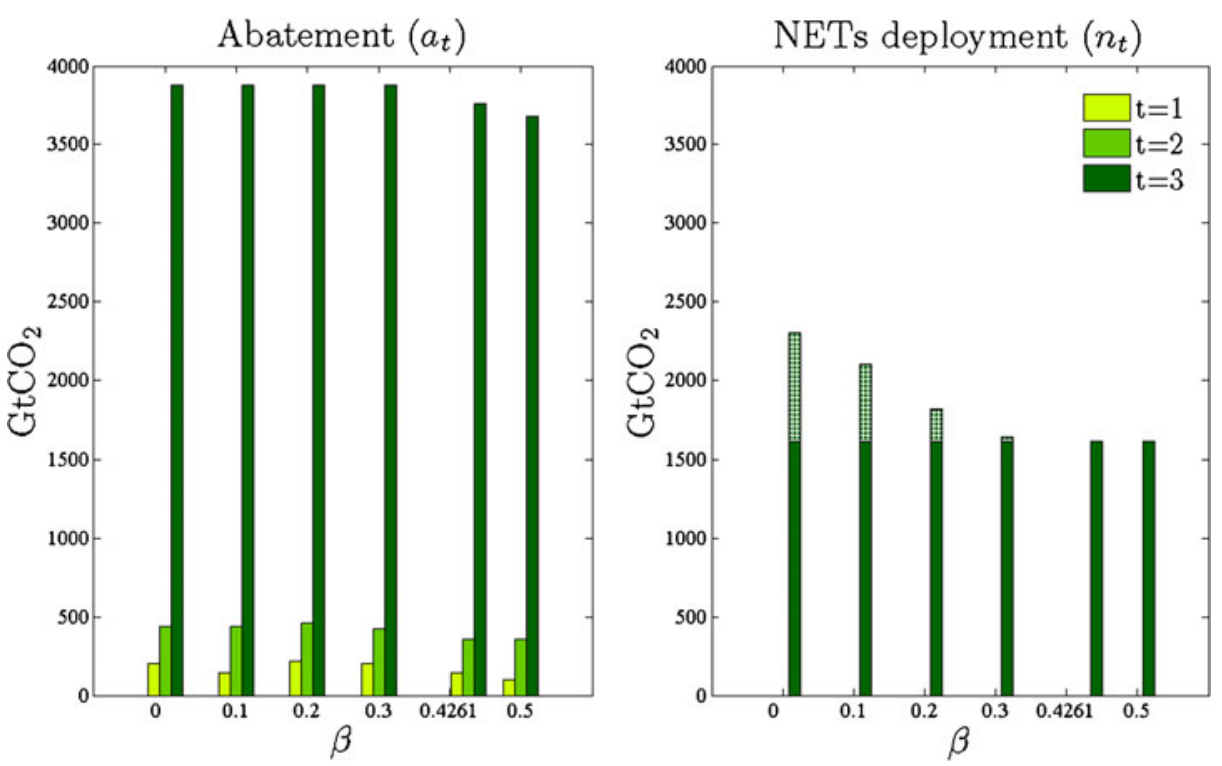

Fig. $2 \mathrm{GtCO}_{2}$ mitigated for different values for $\beta$ (sink's sensitivity to atmospheric $\mathrm{CO}_{2}$ ) in time periods 2010-2029, 2030-2049, 2050-2099

In Fig. 3 we compare the optimal portfolios with different cumulative emission targets. We look at targets that correspond to year $2100 \mathrm{CO}_{2}$ concentration of $390 \mathrm{ppm}, 435 \mathrm{ppm}$, $490 \mathrm{ppm}$ and $550 \mathrm{ppm}^{11}$, i.e. $88 \mathrm{GtCO}_{2}, 880 \mathrm{GtCO}_{2}, 1,500 \mathrm{GtCO}_{2}$ and 2,900 $\mathrm{GtCO}_{2}$ respectively. In terms of NETs deployment we see that if the decision-maker aims for the least stringent cumulative emissions target $\left(2,900 \mathrm{GtCO}_{2}\right)$, NETs are not part of the optimal portfolio anymore. All mitigation is done through abatement, where especially in the medium and long term the amount can also be reduced. At the other end of the spectrum, if the decision maker aims for the lowest target $\left(88 \mathrm{GtCO}_{2}\right)$, the optimal portfolio in the last period contains the maximum amount of $\operatorname{BECCS}\left(1,605 \mathrm{GtCO}_{2}\right)$ plus some $1,035 \mathrm{GtCO}_{2}$ of DAC, as we need so much abatement in the last period that DAC becomes cheaper than the marginal unit of abatement. Independently of the target, period 1 abatement changes from $140 \mathrm{GtCO}_{2}$ for the 88 and 880 targets to only $80 \mathrm{GtCO}_{2}$ for the 1,500 and 2,900 targets.

The present value (PV) of the portfolio cost increases exponentially with the stricter cumulative emissions targets. As can be seen in Fig. 3, the costs of the portfolio aiming at the $88 \mathrm{GtCO}_{2}$ target is 22 times higher than for the portfolio aiming at the $2,900 \mathrm{GtCO}_{2}$ target, and 2.5 times higher than for the $880 \mathrm{GtCO}_{2}$ target.

As many results regarding NETs deployment depend on the potential for BECCS, we perform a sensitivity analysis regarding this variable. The results are shown in Fig. 4, as the BECCS potential introduced in Section 4 is multiplied with 0.5 to 1.5 in every period. We see that even though BECCS is used only in the third period, its potential has a direct impact on the optimal abatement already in the first and second periods. An increase of $50 \%$ in the potential of BECCS is reflected in an over $40 \%$ (20\%) decrease in the first (second) period

\footnotetext{
${ }^{11}$ According to the best estimate of the National Research Council (2011) those concentrations would lead to temperature changes of $1{ }^{\circ} \mathrm{C}, 2.5^{\circ} \mathrm{C}, 4^{\circ} \mathrm{C}$ and $6{ }^{\circ} \mathrm{C}$ if there are no additional emissions.
} 

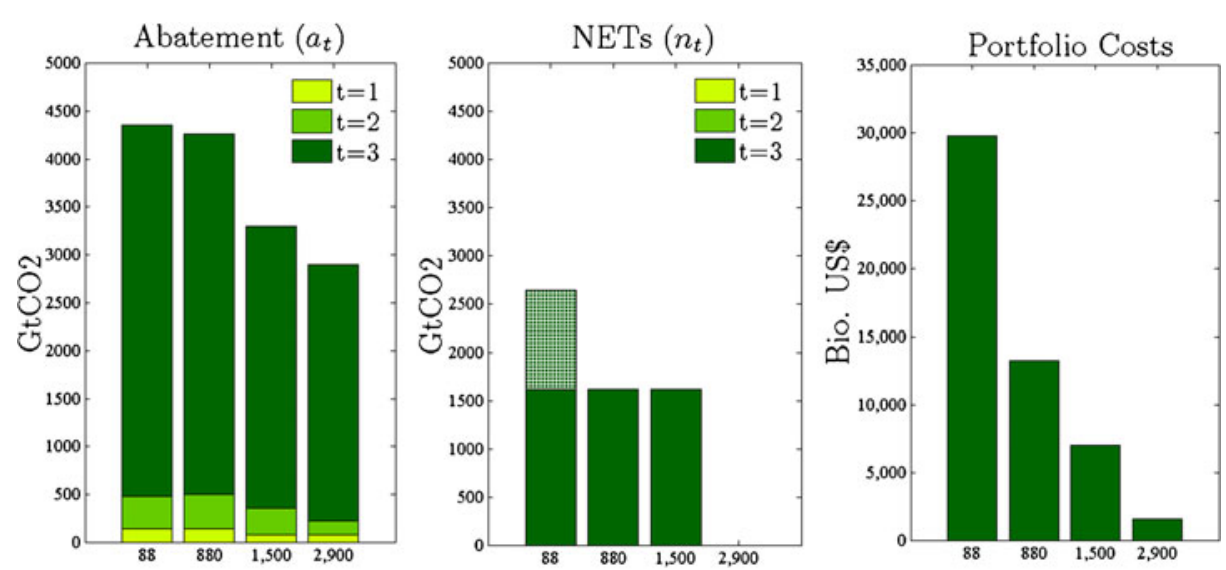

Cumulative Emission Target (GtCO2)

Fig. $3 \mathrm{GtCO}_{2}$ mitigated and PV of optimal portfolio costs in bill. US\$ for different cumulative emission targets $\left(e^{*}\right)$ in time periods 2010-2029, 2030-2049, 2050-2099

abatement. Thus, an underestimation of the real potential would lead to unnecessary high abatement in the first periods, resulting in a lower BECCS deployment in the third period.

If BECCS potentials are higher than in our baseline, i.e. for multipliers of 1.25 or 1.5 , the present value of the portfolio costs as shown in Fig. 4 decrease as we deploy more BECCS up to the new maximum. But this decrease is relatively small compared to the increase if the BECCS potential is lower than in the baseline, i.e. for multipliers of 0.5 or 0.75 . In this case, the PV of the costs almost doubles because of the increased deployment of DAC in the last period.

To conclude, we investigate the reaction of our optimal portfolio to changes in the size $(\delta)$ and probability $(\alpha)$ of a shock to the carbon sink. The respective total emissions to be mitigated by the two options are shown in Fig. 5. It can be seen that with increasing shock size, more mitigation needs to be carried out to get to the target in the last period in total. The
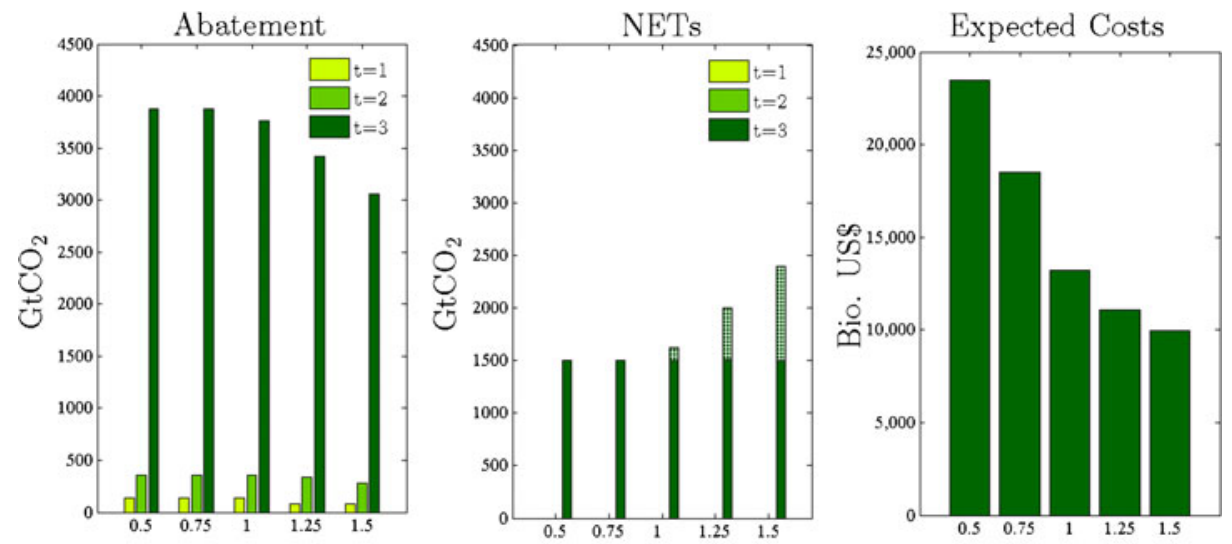

BECCS potential (relative to baseline)

Fig. $4 \mathrm{GtCO}_{2}$ mitigated and PV of optimal portfolio costs in bill. US\$ for different BECCS potentials in relation to baseline assumption in time periods 2010-2029, 2030-2049, 2050-2099 


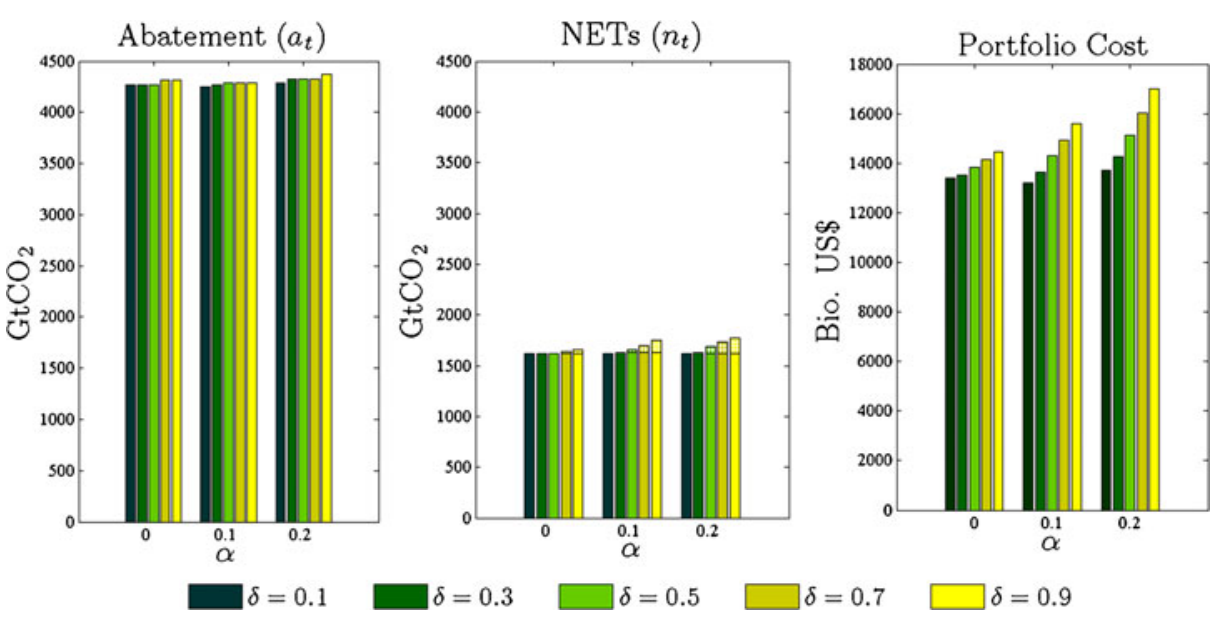

Fig. $5 \mathrm{GtCO}_{2}$ mitigated over the whole planning horizon and PV of the optimal portfolio cost in bill. US\$ for different values of the shock size $(\delta)$ and shock probability $(\alpha)$

larger part of this increase is achieved through NETs deployment. As the potential of BECCS is already fully exploited in the baseline case, the increase can here only happen via a deployment in DAC. With a higher probability of a shock to the sink, this increase with the shock size gets steeper. The PV of the optimal portfolio costs is depicted in Fig. 5. In line with our expectations, the costs increase with the probability and the size of a shock to the carbon sink.

\section{Conclusion}

In this paper, we have addressed the question of how the optimal mitigation portfolio, in which negative emission technology is available to achieve ambitious stabilization targets, is affected by the inclusion of natural sinks conducting a number of sensitivity analyses to account for uncertainty in the underlying parameters.

Results that were shown to be robust across all sensitivity runs indicate that abatement is generally used in all periods, whereas BECCS only in the long-term. Thus, not having BECCS at full disposal for large-scale deployment now might not preclude following the optimal strategy. Furthermore, near-time optimal abatement changes with the expectations of BECCS potentials in the future. Further research to decrease the uncertainty surrounding these potentials is therefore necessary. Another central result of our paper is that sink uncertainty has a positive impact on the cost-optimal adoption of negative emission technologies. If we compare the baseline to the case where shocks are applied to the sink, NETs deployment increases. This implies that neglecting sink stochasticity leads to underestimating the necessary mitigation needs and NETs in particular.

While the qualitative results appear to be stable across different sensitivity analyses of key parameters, there is substantial uncertainty about the true value of climate sensitivity of the sink to the concentration of $\mathrm{CO}_{2}(\beta)$. Future research should look into inclusion of uncertainty about this sensitivity and also about the impact of learning about carbon cycle feedbacks on the structure and temporal deployment of mitigation. Obviously, the result will be influenced by risk preferences, the availability of NETs to offset larger amounts of emissions 
in the last period and the possibility to overshoot in the medium term. Finally, other sources of uncertainty such as the cost of abatement have not been explicitly modeled in this paper, but would be of interest for future research seeking to identify and quantify further tradeoffs within the mitigation portfolio. The same is true for stranded assets as multiple bio-options are deployed over the century. Lastly, the modeling exercise abstracts from issues pertaining to social inertia and public acceptance in particular: specifically pipelines and storage in connection with fossil-based emission sources have been met with significant resistance from residents in affected areas (Wallquist et al. 2012).

Acknowledgments This research has been carried out with support from the EU-funded FP7 projects GEOCARBON, grant number 283080, and GHG-Europe, grant number 244122. The authors are grateful to the editors and three anonymous reviewers for investing substantial effort into helping to improve this work.

Open Access This article is distributed under the terms of the Creative Commons Attribution License which permits any use, distribution, and reproduction in any medium, provided the original author(s) and the source are credited.

\section{References}

Ackerman F, Stanton EA, Bueno R (2010) Fat tails, exponents, extreme uncertainty: simulating catastrophe in DICE. Ecol Econ 69(8):1657-1665

Ahlig R, Adams D, McCarl B, Callaway JM, Winnett S (1997) Assessing effects of mitigation strategies for global climate change with an Intertemporal Model of the US Forsst and Agriculture Sectors. Crit Rev Environ Sci Technol 27:97-111

Allen MR, Frame DJ, Huntingford C, Jones CD, Lowe JA, Meinshausen M, Meinshausen N (2009) Warming caused by cumulative carbon emissions towards the trillionth tonne. Nature 458(7242):1163-1166. doi:10.1038/nature08019

American Physical Society, Socolow, R et al. (eds) Direct air capture of $\mathrm{CO}_{2}$ with chemicals: a technology assessment for the APS panel on public affairs, American Physical Society, Washington DC, 2011, accessible at www.aps.org/policy/reports/assessments/upload/dac2011.pdf

Azar C, Lindgren K, Obersteiner M, Riahi K, van Vuuren DP, den Elzen KMGJ, Möllersten K, Larson ED (2010) The feasibility of low CO2 concentration targets and the role of bioenergy with carbon capture and storage (BECCS). Clim Chang 100(1):195-202

Bosetti V, Carraro C, Sgobbi A and Tavoni M (2008) Delayed action and uncertain targets: how much will climate policy cost?, Nota di lavoro//Fondazione Eni Enrico Mattei: sustainable development, No. 69.2008, accessible at: http://hdl.handle.net/10419/53319

Bosetti V and Lubowski R (eds) (2010) Deforestation and climate change: reducing carbon emissions from deforestation and forest degradation, in: Fondazione Eni Enrico Mattei (FEEM) series on economics, the environment and sustainable development. Edward Elgar, Cheltenham, UK

Caldeira K, Jain AK, Hoffert MI (2003) Climate sensitivity uncertainty and the need for energy without $\mathrm{CO}_{2}$ emission. Science 299:2052-2054

Canadell JG, Raupach M (2008) Managing forests for climate change mitigation. Science 320:1456-1457

Crutzen PJ (2006) Albedo enhancement by stratospheric sulfur injections: a contribution to resolve a policy dilemma? Clim Chang 77(3-4):211-220

Denman K et al (2007) Couplings between changes in the climate system and biogeochemistry. In: Solomon S (ed) Climate change 2007: the physical science basis. Contribution of working group i to the fourth assessment report of the intergovernmental panel on climate change. Cambridge University Press, Cambridge, pp 500-587

Dooley JJ, Dahowski RT, Davidson CL, Bachu S, Gupta N and Gale J (2005) IEA greenhouse gas programme. Proceedings of 7th International Conference on Greenhouse Gas Control Technologies, Volume 1: Peer-Reviewed Papers and Plenary Presentations (ES Rubin, DW Keith and CF Gilboy, eds.), Cheltenham, UK

Fischlin A et al (2007) Ecosystems, their properties, goods, and services. In: Parry ML (ed) Climate change 2007: impacts, adaptation and vulnerability. Contribution of working group II to the fourth assessment 
report of the intergovernmental panel on climate change. Cambridge University Press, Cambridge, pp 211-272

Friedlingstein P et al (2006) Climate-carbon cycle feedback analysis: results from the C4MIP Model Intercomparison. J Clim 19:3337-3353

Fuss S (2010) Forestry carbon sequestration: alternative perspective. In: Lomborg B (ed) Smart solutions to climate change: comparing costs and benefits. Cambridge University Press, Cambridge, pp 133-141

Gerlagh R, Kverndokk S, Rosendahl K (2009) Optimal timing of climate change policy: interaction between carbon taxes and innovation externalities. Environ Resour Econ 43(3):369-390

GEA (2012) global energy assessment - toward a sustainable future. Cambridge University Press, Cambridge UK and New York, NY, USA and the International Institute for Applied Systems Analysis, Laxenburg, Austria

Gough C, Upham P (2011) Biomass energy with carbon capture and storage (BECCS or Bio-CCS). Greenhouse Gases Sci Technol 1(4):324-334

Higgins PAT, Harte J (2012) Carbon cycle uncertainty increases climate change risks and mitigation challenges. J Clim 25:7660-7668

Hoogwijk M, Faaij A, Eickhout B, de Vries B, Turkenburg W (2005) Potential of biomass energy out to 2100 for four IPCC SRES land-use scenarios. Biomass Bioenergy 29(4):225-257

Hope C (2006) The marginal impact of CO2 from PAGE2002: an integrated assessment model incorporating the IPCC's five reasons for concern. Integr Assess J 6(1):19-56

International Energy Agency (2012) Energy technology perspectives 2012: pathways to a clean energy system. OECD Publishing. doi:10.1787/energy_tech-2012-en

IEAGHG (2011) (IEA Greenhouse Gas R\&D Programme): potential for biomass and carbon dioxide capture and storage, 2011/06, July

IPCC (2005) In: Metz B, Davidson O, de Coninck HC, Loos M, Meyer LA (eds) IPCC special report on carbon dioxide capture and storage, prepared by WG III of the Intergovernmental Panel on Climate Change. Cambridge University Press, Cambridge

Kraxner F, Nilsson S, Obersteiner M (2003) Negative emissions from bioenergy use, carbon capture and sequestration (BECS): the case of biomass production by sustainable forest management from seminatural temperate forests. Biomass Bioenergy 24(4-5):285-296

Kraxner F, Aoki K, Leduc S, Kindermann G, Fuss S, Yang J, Yamagata Y, Tak K, Obersteiner M (2012) BECCS in South Korea-analyzing the negative emissions potential of bioenergy as a mitigation tool. Renew Energ. doi:10.1016/j.renene.2012.09.064

Lemoine DM, Fuss S, Szolgayova J, Obersteiner M, Kammen DM (2012) The influence of negative emission technologies and technology policies on the optimal climate mitigation portfolio. Clim Chang 113 (2):141-162

Lehmann J (2007) Bio-energy in the black. Front Ecol Environ 5(7):381-387

Lemoine DM (2010a) Paleoclimatic warming increased carbon dioxide concentrations. J Geophys Res 115: D22122

Lemoine DM (2010b) Climate sensitivity distributions depend on the possibility that models share biases. J Clim 23(16):4395-4415

Le Quéré C et al (2009) Trends in the sources and sinks of carbon dioxide. Nat Geosci 2:831-836

Matthews HD, Gillett NP, Stott PA, Zickfeld K (2009) The proportionality of global warming to cumulative carbon emissions. Nature 459(7248):829-832

McInerney D, Lempert R, Keller K (2012) What are robust strategies in the face of uncertain climate threshold responses? Robust climate strategies. Clim Chang 112(3-4):547-568

Moore B, Allard A (2008) Climate change impacts on forest health. Forest Health \& Biosecurity Working Papers FBS/34E, FAO, Rome, Italy

National Research Council (2011) Climate stabilization targets: emissions, concentrations, and impacts over decades to millennia. The National Academies Press, Washington, D.C.

Nordhaus W (2008) A question of balance: weighing the options on global warming policy. Yale University Press, New Haven

Obersteiner M et al (2001) Managing climate risk. Science 294(5543):786-787

Riahi K et al (2011) RCP8.5 - a scenario of comparatively high greenhouse gas emissions. Clim Chang 109:33-57

Rhodes J, Keith D (2005) Engineering economic analysis of biomass IGCC with carbon capture and storage. Biomass Bioenergy 29(6):440-450

Sohngen B, Mendelsohn R (2003) An optimal control model of forest carbon sequestration. Amer J Agric Econ 85(2):448-457

Stavins RN (1999) The costs of carbon sequestration: a revealed-preference approach. Am Econ Rev 89 (4):994-1009 
The Royal Society (2009) Geoengineering the climate: science, governance and uncertainty, September 2009, London, UK

Van der Zwaan B, Gerlagh R (2009) Economics of geological $\mathrm{CO}_{2}$ storage and leakage. Clim Chang 93 (3):285-309

van Vuuren DP et al (2009) Comparison of top-down and bottom-up estimates of sectoral and regional greenhouse gas emission reduction potentials. Energy Policy 37(12):5125-5139

Van't Veld K, Plantinga A (2005) Carbon sequestration or abatement? The effect of rising carbon proces on the optimal portfolio of greenhouse-gas mitigation strategies. J Environ Econ Manag 50:59-81

Wallquist L, L'Orange Seigo S, Visschers V, Siegrist M (2012) Public acceptance of CCS system elements: a conjoint measurement. Int J Greenh Gas Control 6:77-83 